\title{
REVISÃO CONSTITUCIONAL: UM DESAFIO PARA O BRASIL
}

Aline Bühler*

Resumo: A mudança da Constituição é um tema recorrente no Brasil. A observação desse fenômeno forneceu a temática deste trabalho, que busca desenvolver uma reflexão sobre o instituto da Revisão Constitucional, passando, rapidamente, pela elaboração da teoria que caracteriza a noção de Poder Constituinte.

Palavras-chave: revisão constitucional; poder constituinte; reforma constitucional; poder constituinte reformador.

Abstract: The Constitution Changing is a recurring subject in Brazil's policy. The verification and the observation of this reality inspired the thesis of this article, which main purpose is to think over the principle of Constitution Reviewing, examining the elaboration of the theory that characterizes the notion of Constituent Power.

Keywords: constitutional reviewing, constituent power, constitutional reform, constitutional reform power.

\section{Introdução}

Este artigo tem como principal objetivo desenvolver uma reflexão crítica sobre o instituto da revisão constitucional e demais questões que nela estão subjacentes. A análise desse tema devese, principalmente, aos intensos debates travados na Câmara dos Deputados sobre a possibilidade de uma nova revisão constitucional. O Congresso Nacional esteve discutindo a Proposta de Emenda à Constituição - PEC n. 157 de 2003, que pretendia convocar uma Assembléia de Revisão Constitucional para a próxima legislatura.

Sempre que há uma situação ou ameaça de crise, alguns setores retomam a tese da revisão constitucional, como aconteceu em 1997 com a proposta do deputado Miro Teixeira. Sua PEC, de n. 554/97, foi lançada quando se discutiam várias emendas constitucionais (reforma administrativa e

Assessora Parlamentar na Câmara dos Deputados; Especialista em Processo Legislativo pelo Programa de PósGraduação do Centro de Formação, Treinamento e Aperfeiçoamento da Câmara dos Deputados; aline.buhler@camara.gov.br 
previdenciária, sistema tributário, quebra de monopólio, sistema eleitoral e partidário e principalmente a emenda da reeleição) e visava convocar um Congresso revisor para aprovar essas reformas com um quorum de maioria absoluta. Essa proposta está parada na Câmara até hoje.

A Constituição Federal é a lei fundamental do país, é o modelo de tudo o que se faz no Brasil no tocante a leis e atos normativos. Não é estática nem eterna, ela pode ser transformada por meio de emendas constitucionais, como prevê seu próprio texto, e conforme as necessidades da sociedade. Esse fato é aceitável, visto que os costumes e as práticas da sociedade não estão engessados, mas passam por constantes alterações que precisam ser refletidas nos estatutos que ordenam as relações entre seus componentes, sejam indivíduos, sejam instituições.

Mas é também notória, no Brasil, uma tendência à instabilidade do texto legal, refletindose tal fenômeno na constante necessidade de se rever, emendar e reformular as leis em geral e o ordenamento constitucional em particular. Exemplo disso são as 53 emendas constitucionais aprovadas pelo Congresso Nacional até início de 2007, mais as centenas de propostas de emenda que tramitam nas duas Casas.

Antes de adentrarmos no tema proposto, faz-se necessário explicar, rapidamente, a elaboração da teoria que caracteriza a noção de Poder Constituinte, seu conceito, natureza, titularidade e limites, traçando a base do estudo. $\mathrm{O}$ assunto da oportunidade, da propriedade, da amplitude e dos limites da revisão constitucional encontra nos diversos autores do Direito Constitucional, nacionais e estrangeiros, vários referenciais teóricos e práticos a respeito do poder constituinte e do poder de reforma.

Ao final deste trabalho, pretende-se ter alcançado um modesto debate em torno do poder constituinte reformador, tendo como foco a oportunidade que se descortina de uma revisão constitucional no país. Uma discussão que, espera-se, seja frutífera, embora não seja nova.

\section{Noções do Poder Constituinte}

É na Europa, no final do século XVIII, que surge a teoria do poder constituinte. Ligada à idéia de Constituição escrita, teve como principal doutrinador o pensador e revolucionário francês Emmanuel Joseph Sieyès. Suas idéias, que surgem imersas na crise do pensamento absolutista e na antevéspera da Revolução Francesa, em linhas gerais, propunham uma nova representação nos Estados Gerais, redefinindo o espaço político do Terceiro Estado.

A sociedade francesa dessa época era estratificada. No topo da pirâmide social estava o clero, Primeiro Estado, com todos os privilégios; logo abaixo, estava a nobreza, Segundo Estado; e na base da sociedade, o Terceiro Estado formado pelos camponeses, trabalhadores e burgueses. 
Estes arcavam com o peso de impostos para o rei, o clero e a nobreza, que tinham isenção tributária. Essa injustiça social perdurou por décadas, até culminar com a Revolução Francesa.

Sieyès era representante do Terceiro Estado e teve participação ativa na revolução. Publicou o panfleto "Qu'est-ce que le Tiers État?", que o notabilizou ao divulgar uma série de demandas da “classe laboriosa” (SIEYÈS, 2001, p. XXIX). A principal reivindicação do Terceiro Estado era a abolição dos privilégios e a instauração da igualdade civil e política. Afirmava que o Terceiro Estado era uma nação completa, pois os trabalhos que sustentavam a sociedade recaíam sobre ele. A supressão das ordens privilegiadas não prejudicaria em nada a nação, pelo contrário, iria libertá-la. Sustentava que era um direito do Terceiro Estado a escolha de seus representantes dentre os cidadãos das classes que o compunham, que esses representantes fossem em número igual ao do clero e da nobreza e, ainda, que os votos fossem por cabeça e não por ordem. Visando essas mudanças, defendeu que só havia uma forma de acabar com as diferenças: fazendo uma Constituição; e mais, que "só a nação tem direito de fazê-la" (SIEYÈS, 2001, p. 45), sua vontade era a própria lei. Defendia a formação de um corpo de representantes extraordinários, que seria designado unicamente para essa finalidade e por tempo determinado. Esses representantes seriam independentes, não estando subordinados a qualquer forma ou condição. A concepção de nação soberana, como titular do poder constituinte e expressão da vontade permanente da comunidade, aperfeiçoou-se nessa época. Coube a Sieyès esboçar a distinção entre poder constituinte, que reside sempre no povo e estabelece a Constituição, e poderes constituídos, que derivam do poder constituinte e a ele estão subordinados.

Manuel Gonçalves Ferreira Filho destaca que a teoria de Sieyès surge exatamente para justificar a criação da constituição escrita. Resume as idéias de Abade dizendo que todo Estado deve ter uma Constituição, e que ela é "obra de um Poder, o Poder Constituinte, que é anterior à Constituição, precede, necessária e logicamente, a obra que é a Constituição. O Poder Constituinte, portanto, gera os Poderes do Estado, os poderes constituídos, e é superior a estes" (FERREIRA FILHO, 2005, p. 13).

Assim, cumpre distinguir poder constituinte originário e poder constituinte derivado ou reformador. Poder Constituinte originário é "a manifestação soberana da suprema vontade política de um povo, social e juridicamente organizado" (MORAES, 2003, p. 54). É o poder fundador, que cria e organiza o Estado. Esse poder é exercido quando as condições sócio-políticas do país encontram-se em crise, exigindo uma nova Constituição. Por ser o povo titular do poder constituinte originário, cabe a ele delegar a seus representantes esse poder, que não se esgota em um ato de seu exercício, pois o poder constituinte é permanente, inalienável e incondicionado. 
Contrapondo-se a esse poder, têm-se os poderes constituídos, criados pelo poder constituinte, dentre os quais o Poder Legislativo. A esse poder constituído deu-se a possibilidade de emendar a Constituição, reformá-la por meio de um processo especial estabelecido em seu texto. É o denominado poder constituinte derivado ou reformador, instituído na Constituição.

É bom lembrar que, quando se fala em poder de reforma, presume-se que essa Constituição passível de alteração seja rígida - aquela que só pode ser modificada por procedimento especial pois as constituições flexíveis se caracterizam pela possibilidade de serem alteradas pelo processo legislativo ordinário. De nada adiantaria emanar do povo o poder constituinte, se os legisladores pudessem modificar a ordem constitucional sem qualquer obstáculo. Portanto, existem limites que a própria Constituição impõe para sua modificação.

Assim, a mudança formal da Constituição está sujeita a limitações. As constituições rígidas estabelecem procedimentos especiais a serem observados pelo órgão do poder de reforma. São os chamados limites formais, que dizem respeito à competência, às regras para votação, aprovação e promulgação. Há também as limitações temporais, na qual o tempo surge para o legislador como um obstáculo, até atingir o limite fixado. As limitações circunstanciais são aquelas que impedem a reforma do texto constitucional em situações anormais, que possam interferir na livre manifestação do órgão reformador. Finalmente, temos as limitações materiais, também chamadas de limites de fundo, onde o poder de reforma não pode atingir determinados dispositivos da Constituição. São limitações de conteúdo, não de forma, e podem ser explícitas ou implícitas.

As limitações explícitas são aquelas enumeradas no texto constitucional, previstas textualmente pelo poder constituinte originário. Na Constituição brasileira, esses limites visam proteger os princípios federativo e democrático, bem como os direitos e garantias fundamentais.

Em relação aos limites implícitos, a doutrina brasileira admite sua existência, na tese do professor Nelson de Souza Sampaio (1954). Entende ele que o poder de reforma não pode alterar as normas relativas aos direitos fundamentais (no caso brasileiro essas normas se constituem em cláusulas pétreas); a titularidade do poder constituinte; nem a titularidade do próprio poder reformador, pois não poderia o legislador ordinário ir contra a vontade do poder constituinte originário. $\mathrm{O}$ outro limite implícito sustentado pelo autor é justamente a proibição de alteração no processo que disciplina a reforma constitucional.

Assim, o poder constituinte originário criou um poder constituinte instituído, ou reformador, mas que é subordinado, secundário e condicionado, devendo respeitar as limitações jurídicas traçadas pelo constituinte originário. 


\section{Revisão Constitucional}

O poder constituinte de reforma é um poder derivado do poder constituinte originário, por meio do qual se pode modificar a constituição, conforme os procedimentos nela estabelecidos. Na Constituição brasileira, há previsão de duas espécies de reforma: a revisão constitucional e a emenda à Constituição.

A doutrina não é precisa no emprego dos termos reforma, emenda e revisão constitucional, sendo empregados indistintamente por alguns doutrinadores. Contudo, filiamo-nos, como José Afonso da Silva (2002, p. 242), à corrente que entende ser o termo "reforma" gênero que abrange as espécies: emenda (mudanças pontuais) e revisão (modificações mais amplas). Essa distinção foi adotada pela Constituição Federal de 1988, que disciplina, em seu art. 60, as emendas como forma regular de alteração do texto, tratando da revisão constitucional no art. $3^{\circ}$. do Ato das Disposições Constitucionais Transitórias.

Ao fazer essa distinção, quis o constituinte originário autorizar uma única revisão. Essa revisão ocorreu em 1993, esgotando-se, assim, tal possibilidade. Uma vez ultrapassada a revisão estatuída, só resta a reforma constitucional por meio de emendas ao texto da Carta Magna. Essa é uma garantia da estabilidade constitucional, segurança jurídica e da manutenção do Estado de Direito. Logo, a possibilidade de uma dupla revisão não pode mais ser legitimamente estabelecida na ordem constitucional vigente. Mas essa posição não é pacífica dentre os doutrinadores. Aliás, a celeuma é grande quando se estuda esse tema.

Dentre as diversas discussões que surgem, uma em especial se destaca: pode o Poder Constituído, ou seja, poder limitado e condicionado às normas constitucionais vigentes, propor uma revisão constitucional que não está prevista no ordenamento jurídico atual por meio de uma emenda à Constituição?

Manoel Gonçalves Ferreira Filho (2005) aborda em seu livro O Poder Constituinte a possibilidade de a revisão constitucional ser proposta por uma emenda à Constituição. Para subsidiar quem defende essa idéia, relata casos do direito pátrio e comparado em que as regras foram alteradas para facilitar essas mudanças do texto constitucional. No Brasil, cita o caso da Emenda Constitucional n. 26/85, que convocou a Assembléia Constituinte da qual derivou a atual Constituição. Lembra que os juristas opostos à revisão também têm seus argumentos, como a limitação geral ao poder de mudar a Constituição. Mas claramente se posiciona favorável à tese da possibilidade de uma nova revisão, entendendo que não existem impedimentos jurídicos para sua convocação. E mais, defende a possibilidade de revogação das cláusulas pétreas, condenando a "intocabilidade absoluta". 
Já outros autores ${ }^{1}$ tecem suas críticas à reforma constitucional apoiando-se na tese de que a permanência de uma Constituição vai depender da sua aptidão de traduzir os valores que informam a sociedade. José Afonso da Silva (2002) alerta para o processo de retalhação que sofre a Constituição de 1988. Os constantes emendamentos têm transformado sua fisionomia, de relevante papel social, para uma feição neoliberal, visando os interesses da elite. Classifica como inconstitucionais as tentativas de instaurar nova revisão constitucional por processo simplificado, pois estas ferem de morte cláusula pétrea implícita. Assim, qualquer tipo de emenda tendente a modificar o procedimento de reforma da Constituição (limitação formal) cria uma situação não estabelecida pelo poder constituinte originário, ou seja, o poder derivado estaria usufruindo de poderes que não lhe foram concedidos. Entende, ainda, que tal hipótese infringe o princípio da supremacia da Constituição, pois o processo de revisão estabelecido no art. $3^{\circ}$ do ADCT, de eficácia exaurida, esgotou-se com sua realização em 1993.

Outro argumento dos defensores da revisão é de que, uma vez sendo aprovada pela consulta popular, não haveria ilegitimidade na mesma, pois a vontade popular legitimaria a alteração. Quando se fala em aprovação popular direta, soberania popular, não se trata de colocar para o povo brasileiro as alterações propostas pelos parlamentares, para que então se aceite ou não essas mudanças. O referendo, embora exercício direto do poder, não legitima necessariamente um ato, pois é preciso que o povo esteja ciente do que está nas suas mãos. Exemplo disso foi o referendo das armas, cujos programas de divulgação foram apelativos e não instrutivos. As pessoas não sabiam o teor da norma que iriam aprovar ou rejeitar, pois as campanhas publicitárias apresentaram, apenas, a realidade violenta em que nossa sociedade está inserida, números da tragédia urbana em que vivemos, trabalhando com o medo da população. Para que haja legitimidade, precisa primeiro haver conhecimento, informação, participação popular. Quando se fala em poder do povo, na população pedindo mudanças, significa que os brasileiros, com movimentos sociais, intensos e gerais, devem exigir um novo texto constitucional, uma revisão das normas vigentes. E isso não está ocorrendo hoje.

\section{Conclusão}

Entendemos que não pode um poder constituinte derivado, regrado, condicionado e limitado, fruto do poder constituinte originário, gerar outro poder constituinte derivado para alterar a Constituição por procedimento diverso do existente, criando situações que não foram previstas por quem de direito, ou seja, o constituinte originário. Os procedimentos estabelecidos para a reforma do texto constitucional são limitações essenciais e inafastáveis. São eles que caracterizam as

\footnotetext{
${ }^{1}$ Nesse sentido, temos: José Afonso da Silva; Vicente Paulo; Fábio Konder Comparato; Paulo Bonavides.
} 
constituições rígidas. O Congresso Nacional não pode se atribuir mais poder. Isso seria extrapolar a distribuição de poderes estabelecidos na Constituição. A Carta pode e deve ser reformada, para que acompanhe a evolução do pensamento do corpo social, mas pelo processo de emendas constitucionais já estabelecido em seu texto.

A onda reformista atualmente verificada é fruto de interesses políticos e da prolixidade do texto constitucional vigente. Porém, mais do que reformar a Constituição, é preciso cumprir e fazer com que se cumpram os princípios e as normas nela consagrados. A desobediência da ordem estabelecida sob o apelo reformador, no interesse de grupos que buscam nada mudar, pode ensejar o que há de mais grave em todo o sistema jurídico: a descrença do povo nas suas próprias leis, e o que é pior, que sua Lei Maior é inútil, ou ainda, instrumento de poucos em detrimento de muitos.

\section{Referências}

FERREIRA FILHO, Manoel Gonçalves. O poder constituinte. 4. ed. São Paulo: Saraiva, 2005. MORAES, Alexandre de. Direito constitucional. 14. ed. - São Paulo: Atlas, 2003. SAMPAIO, Nelson de Sousa. O poder de reforma constitucional. - Bahia: Progresso, 1954. SIEYÈS, Emmanuel Joseph. A constituição burguesa. Qu'est-ce que lê Tiers État? (tradução Norma Azevedo) 4.ed. Rio de Janeiro: Lumen Júris, 2001.

SILVA, José Afonso da. Poder constituinte e poder popular: estudos sobre a Constituição. São Paulo: Malheiros - 2002. 